\title{
Increased resistance to extinction as a function of the opportunity to retrace in the runway ${ }^{1}$
}

MELVIN H. MARX

UNIVERSITY OF MISSOURI, COLUMBIA

\begin{abstract}
Markedly superior resistance to extinction in the runway was shown by rats which were allowed to retrace immediately after entering the goalbox and receiving a buzzer cue formerly associated with reinforcement. Rats also receiving this cue immediately but not allowed to retrace showed reliably less resistance to extinction. Two corresponding groups with delayed reinforcement and cue showed poorer acquisition and extinction performance.
\end{abstract}

This experiment was designed to determine if the presentation of a training cue associated with reinforcement would increase resistance to extinction in animals given an opportunity to retrace from the goalbox as well as those maintained in the goalbox in the ordinary manner. Four groups of rats were trained and tested in the runway. They were differentiated, in a 2 by 2 factorial design, by delay of reinforcement ( 0 or $20 \mathrm{sec}$ ) and extinction procedure (presence or absence of opportunity to retrace). This factorial design was a combination and replication of similar experimental conditions used previously (Marx, 1967). In the two earlier experiments, evidence of an apparent reinforcing property associated with retracing from the goalbox was obtained.

Subjects and Apparatus

A total of 32 young naive Sprague-Dawley female rats was randomly divided into the following four groups: I-R (immediate-retrace); I-N (immediate-no retrace); D-R (delayed-retrace); and $\mathrm{D}-\mathrm{N}$ (delayedno retrace). A standard runway was used. It had a 16 in. startbox, 36 in. alley, and 16 in. goalbox, all $3-1 / 2$ in. high and $3-1 / 2$ in. wide. It was painted a flat gray, except for the goalbox, the sides of which were painted with 1 in. vertical black and white stripes. Procedure

All Ss were placed on a $23 \mathrm{~h}$ food deprivation schedule five days before the initiation of training, with $8 \mathrm{~g}$ food provided daily throughout the experiment. In training, 10 trials per day for five days were given, with an intertrial interval (ITI) of $30 \mathrm{sec}$. The runway was cleaned after each $S$ had completed its 10 trials. Groups I-R and I-N received a buzzer cue along with one Noyes pellet $(45 \mathrm{mg})$ reinforcement as soon as they entered the goalbox. Groups D-R and D-N received the buzzer cue and food reinforcement $20 \mathrm{sec}$ after entering the goalbox. All Ss were removed from the goalbox $30 \mathrm{sec}$ after entering. Start time (ST) and run time (RT) were recorded.

In extinction, which was massed, a total of 50 trials was given, again with a 30 sec ITI. S was removed from the runway if it failed to enter the goalbox within $90 \mathrm{sec}$. When the goalbox was entered, $S$ was removed from the runway 30 sec later. Groups $\mathrm{I}-\mathrm{N}$ and $\mathrm{D}-\mathrm{N}$ were treated just as in training except that no food was provided. Groups $I-R$ and $D-R$ had the goalbox door reopened $3 \mathrm{sec}$ after $\mathrm{S}$ entered the goalbox, and retracing was thereby permitted. Exits from and reentries into the goalbox were recorded. Results

Figure 1 shows the reciprocals of mean RT for the last block of 10 training trials. The I groups learned normally, whereas the $D$ groups showed little improvement. Since the retrace variable was not in effect in acquisition, an analysis appropriate to a one factor experiment was performed. The difference was highly reliable $(F=60.54, d f=1 / 30, p<.01)$. Similar results were obtained for ST $(F=20.68$, df $=1 / 30, \mathrm{p}<.01$ ).

Reciprocals of mean RT in extinction are plotted for the four groups in Fig. 1. It is quite evident that the most important difference was the increased resistance to extinction shown by Group I-R. The delay variable was reliable at the .01 level of confidence ( $F=19.04$, df $=1 / 28)$, indicating superior per-

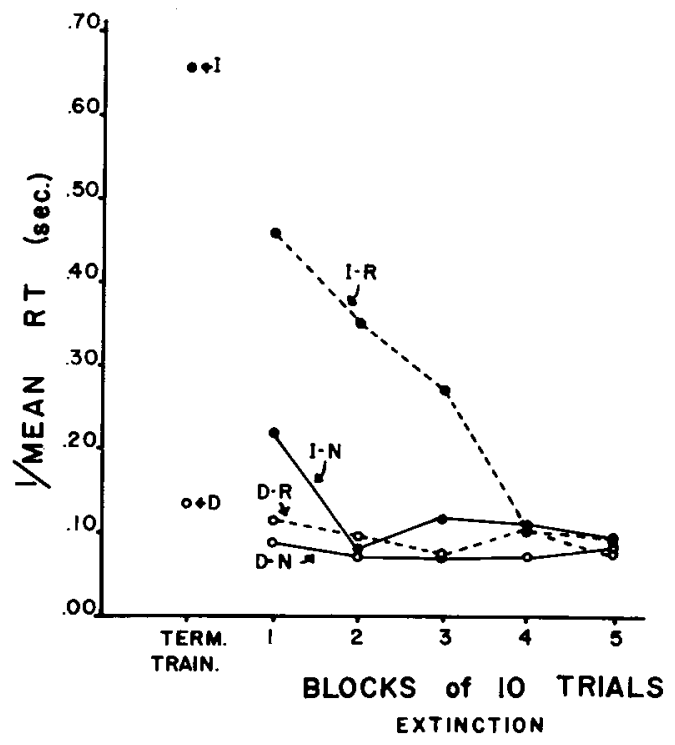

Fig. 1. Reciprocals of Mean Running Times for the last Block of Trials in Acquisition and for the Five Blocks of Trials in Extinction. 
formance by Groups I-R and I-N. The retrace variable was also reliable at the .01 level $(F=9.12, d f=1 / 28)$, indicating superior performance by Groups $I-R$ and D-R. Furthermore, the interaction between the delay and retrace variables was reliable at the .05 level $(F=4.96, \mathrm{df}=1 / 28)$. A breakdown of the analysis indicated that Group $I-R$ was reliably more resistant to extinction than Group I-N $(F=13.79, p<.01)$, but Groups D-R and D-N did not differ $(F<1.00)$.

A similar trend, but with much reduced group differences, was found for ST. Here the overall group effect was not reliable $(F=1.60, d f=1 / 28, p>.10)$.

A number of comparisons were made of the goalbox behavior of the two retrace groups. Group I-R Ss left the goalbox reliably sooner $(F=6.40, \mathrm{df}=1 / 14$, $\mathrm{p}<.05)$, reliably more often within the first $20 \mathrm{sec}$ of confinement $(F=6.84, p<.05)$, reliably more frequently $(F=7.02, p<.05)$, and on a reliably greater proportion of all trials $(F=7.41, p<.05)$. Group $D-R$ Ss spent more time in the goalbox $(F=9.54, p<.01)$. There was no difference in the number of exits within the last $10 \mathrm{sec}$ of goalbox confinement, after the buzzer cue $(F<1.00)$.

\section{Discussion}

The marked inferiority in training and extinction shown by the delayed Ss is consistent with earlier results (Marx, 1967) and the recent runway results of Tombaugh (1966). Because of this great difference in training, differences in extinction between delayed and immediate Ss cannot be clearly interpreted. The failure of delayed Ss to train adequately likewise reduced the meaningfulness of any evaluation of the motivating role of the delayed cue in the retrace situation. The prediction that the delayed cue would serve as a strong motivator and maintain resistance to extinction even in the retrace condition could therefore not be properly tested.

The one result of interest that did emerge from these data concerns the marked increment in resistance to extinction of Group I-R. Like the results previously reported (Marx, 1967), this result is clearly contradictory to the reduced resistance to extinction earlier reported for retrace Ss by Adelman \& Maatsch (1955). A major procedural difference between the Adelman and Maatsch experiment and the present experiment involves the use of the buzzer cue. The question arises: Did the opportunity to retrace immediately after the cue weaken the inhibitory effect of this cue, as compared with the enforced inactivity which followed it in Group I-N? A direct test of this implication of the results might well be fruitful in casting light on the role of secondary reinforcing cues in extinction.

More generally, the fact that Group I-R Ss were clearly more active in leaving the goalbox than those of any other group, and yet equally clearly showed the greatest resistance to extinction, raises a serious question about the interference theory of extinction. That is to say, if extinction is a function of the learning of interfering responses, why did not Group I-R show faster extinction, since it had the most opportunity to learn interfering responses?

Apart from this question, the obtained results confirm the earlier ones in suggesting that being permitted to leave the goalbox-even to retrace-is more "reinforcing" than enforced confinement in the goalbox. This fact offers empirical support complementary to the runway results recently reported by Tombaugh (1966). He showed that shifting from a 20 sec goalbox confinement in acquisition to a 0 sec confinement in extinction resulted in reliably greater resistance to extinction than either two 20 sec or two $0 \mathrm{sec}$ confinements. Considered together, these two sets of data provide strong evidence for the inhibitory influence of prolonged goalbox confinement in extinction.

On the positive side, the present results and those previously reported (Marx, 1967), in the light of the role apparently played by the secondary reinforcing (motivating) cue, are seen as offering some support for the motivational account of extinction (Marx, 1966).

\section{References}

ADELMAN, H. M., \& MAATSCH, J. L. Resistance to extinction as a function of the type of response elicited by frustration. $J$. exp. Psychol, 1955, 50, 61-65.

MARX, M. H. The activation of habits. Psychol Rep., 1966, 19, 527-550.

MARX, M. H. Resistance to extinction as a function of delay of reinforcement and the opportunity to retrace. Psychon. Sci, 1967, 8, 287-288.

TOMBAUGH, T. N. Resistance to extinction as a function of the interaction between training and extinction delays. Psychol Rep., 1966, 19, 791-798.

Note

1. This research was supported in part by USPHS Research Grant HD-00895 from the National Institute of Child Health and Human Development and by USPHS Research Career Award 1-K6-MH-22,023 from the National Institute of Mental Health. The author wishes to thank Phillip D. Wann for his assistance in the collection of data. 